\title{
Inovações pedagógicas no ensino superior: a problematização e o porttólio na formação de pedagogos
}

\author{
Marina Lemos Villardi ${ }^{1}$ \\ Eliana Goldfarb Cyrino ${ }^{2}$
}

\section{Resumo}

A fim de qualificar as propostas de ensino/aprendizagem, as Instituições de Ensino Superior na formação de pedagogos devem pautar-se em práticas inovadoras em educação. Assim, uma Instituição privada de Ensino Superior do interior paulista, busca desenvolver, em uma de suas disciplinas oferecidas ao curso de Pedagogia, práticas de ensino problematizadoras e o uso do portfólio reflexivo. O estudo tem como objetivo relatar as contribuições da Metodologia da Problematização e do portfólio reflexivo na formação do pedagogo, bem como os desafios que os cercam. Trata-se de um estudo exploratório e descritivo sobre o desempenho dos alunos com a Metodologia da Problematização e com o uso do portifólio. É possível afirmar o cumprimento efetivo das etapas da Metodologia da Problematização neste estudo. Ressalta-se como contribuições: aproximação entre teoria e prática, o desenvolvimento da capacidade comunicacional e o trabalho em equipe. Como fragilidades, destacam-se a sistematização das informações no portfólio.

Palavras- chave: Aprendizado Ativo. Currículo. Formação de professores.

\begin{abstract}
In order to qualify education proposals, the Institutions of College Education in the pedagogues' graduation/training should guide themselves in innovative practices in how to teach. Thus, a private Institution of College Education in the countryside of São Paulo pursuit to develop in one of its subjects offered to the Pedagogy course teaching problematizing practices and the thoughtful portfolio in use. The study has as a goal to report the contributions to the Problematization Methodology and to the thoughtful portfolio inside the de pedagogue's training as well as challenges surrounding them.It is about and exploratory and descriptive study of students performance with the Problematization Methodology. It is possible to claim the effective accomplishment in the steps of Problematization Methodology in this research. To emphasize as contributions: the approach between theory and practices, development of communication skills and the team work. Considering the weaknesses we highlight the information systematization in the portfolio.
\end{abstract}

Keywords: Active learning. Resume. Teacher's training.

\footnotetext{
${ }^{1}$ Pós-Doutorada pela FMB-UNESP em Metodologias inovadoras do ensino superior. Doutora e Mestre em Saúde Coletiva pela Universidade Estadual Paulista Júlio de Mesquita Filho/Faculdade de Medicina de Botucatu -FMB - UNESP. Graduada em Pedagogia pela Faculdade de Ciências na Universidade Estadual Paulista Júlio de Mesquita Filho - UNESP/ Bauru. Atualmente é Coordenadora do curso de Pedagogia do Centro Universitário Sudoeste Paulista- UNIFSP (Avaré-SP). E-mail: mavillardi@yahoo.com.br

${ }^{2}$ Médica pela Faculdade de Medicina de Jundiaí. Mestre em Medicina Preventiva e Social pela Faculdade de Medicina da USP e em Educação Para Profissionais de Saúde, na University of Illinois, Chicago, EUA. Doutora em Pediatria pela FMB, UNESP. Professora Associada do Depto de Saúde Pública da FMB, UNESP. Atualmente é supervisora do Centro de Saúde Escola de Botucatu, Unidade da FMB, UNESP. E-mail: ecyrino@, fmb.unesp.br
} 


\section{Introdução e Fundamentação Teórica}

A Universidade, na intenção de fazer rupturas com a racionalidade técnica, tem sido objeto de inovações que buscam nova configuração de saberes. Entretanto essas experiências nem sempre são frequentes, havendo o interesse em desenvolver pesquisas neste contexto a fim de contribuírem para a mudança paradigmática. A formação de professores, por muitas vezes, é tratada em uma dimensão neutra, quer na sua inspiração pedagógica, quer na perspectiva psicológica (CUNHA, 1989).

Práticas e metodologias inovadoras são mais raras na Educação Superior do que em outros níveis de ensino. Isto porque os professores das universidades são, geralmente, resistentes a mudanças por estarem ligados à uma concepção de ciência e educação tradicionais. Na recente tradição universitária, a docência em si mesma dificilmente constituía um assunto de destaque para o ensino superior, ou seja, não existiam iniciativas relevantes para a qualidade do processo formativo (ZABALZA, 2006).

Contudo, essa realidade está se modificando, considerando-se a importância da formação profissional dos alunos e a necessidade de refletir sobre o tipo dessa formação e o objetivo do curso de Pedagogia nesse processo, o que requer pensar em estratégias de aprendizagem condizentes com o contexto social em que vivemos.

O curso de pedagogia destina-se à formação de profissionais interessados em estudos do campo teórico-investigativo da educação e no exercício técnico-profissional como pedagogos no sistema de ensino, nas escolas e em outras instituições educacionais, inclusive as não-escolares. Assim são objetivos dos cursos de pedagogia: preparar professores capazes de integrar-se na elaboração coletiva e avaliação da proposta pedagógica da escola, investigar problemas do cotidiano escolar mediante reflexão e teorização contextualizada, desenvolver práticas educativas que garantam a qualidade da educação (ROMANOWSKI, 2012)

Assim, a fim de qualificar as propostas de ensino/aprendizagem, as finalidades sociais das Instituições de Ensino Superior na formação de pedagogos devem pautar-se em práticas que desafiem o aluno, mediante a inclusão de situações que despertem para problemas do cotidiano, em busca de superar a alienação na formação discente (PIMENTA; ANASTASIOU, 2010).

Isto porque quando os alunos estão envolvidos em aprendizagens significativas, são mobilizados na sua totalidade, despertando emoção, cultura e atitudes. Neste contexto o professor/formador tem a responsabilidade de ajudar o formando a desenvolver, de maneira gradativa, a capacidade de transformar a informação em conhecimento, como esclarece Cunha (2010).

Diversos professores universitários, já conscientes dessa realidade e da necessidade da mudança, buscam desenvolver práticas diferenciadas do tradicional ensino bancário como discute Freire (2002) e sugerem estratégias mais colaborativas entre os estudantes. Estas práticas procuram promover uma construção e apropriação significativa dos conteúdos, habilidades e competências necessárias para a formação profissional e humana de seus alunos, são as chamadas "inovações pedagógicas".

Cunha (2004) esclarece o conceito de inovação pedagógica que significa não apenas a inclusão de novidades e tecnologias, mas também uma mudança na forma de entender o conhecimento. Dentre as características de inovações pedagógicas, destacam-se: a ruptura com a forma tradicional de ensinar e aprender; a gestão participativa com a atuação dos estudantes na definição de percursos e critérios no ensino; a reconfiguração de saberes incluindo também competências, arte, vivências pessoais; a reoganização da relação entre a teoria e a prática; a modificação 
da percepção da concepção, desenvolvimento e avaliação da experiência no ensino/aprendizagem; a mediação do docente assumindo relações sócio-afetivas com os alunos como condição de aprendizagem significativa (subjetividade, conhecimento); o protagonismo como condição para aprendizagem significativa, reconhecendo que tanto estudantes quanto professores são sujeitos da prática pedagógica estimulando a produção de conhecimento pelos estudantes.

Neste contexto, enquadram-se novos referenciais problematizadores para a educação superior, como a Metodologia da Problematização (MP) com o arco de Maguerez, por exemplo, que promove a mobilização do potencial social, político e ético dos alunos, pois os alunos são levados a observar a realidade de uma maneira atenta e identificar aquilo que está se mostrando como preocupante e concretiza-se através de um processo criativo que envolve ação-reflexão sobre um aspecto da realidade observada e, como consequência, alguma transformação deverá ser realizada (BERBEL, 1998, 1999, 2012; VILLARDI; CYRINO; BERBEL, 2014; VILLARDI, CYRINO; BERBEL, 2015).

A Metodologia da Problematização, buscada nas mudanças curriculares nos cursos de graduação no Brasil, é sustentada no referencial teórico de Freire, marcada pela busca das transformações da sociedade pela prática conscientizadora, como se lê em Cyrino e Pereira, 2004; Cyrino e Rizzato, 2004; Miranda e Barroso, 2004; Backes et al., 2007; Mitre et al., 2008; Rodrigues e Caldeira, 2008; Marin et al., 2010; Borille et al., 2012.

A seguir apresentam-se, detalhadamente, as etapas que compõem o caminho didático da Metodologia da Problematização, conforme descrição de Berbel (1998; 1999; 2012) e Colombo e Berbel (2007). São cinco etapas que se desenvolvem a partir da realidade ou de um recorte da mesma e para a realidade retorna: a observação da realidade e a identificação do problema, os pontos-chave, a teorização, as hipóteses de solução e aplicação à realidade, configuram-se na figura de um Arco, o Arco de Marguerez:

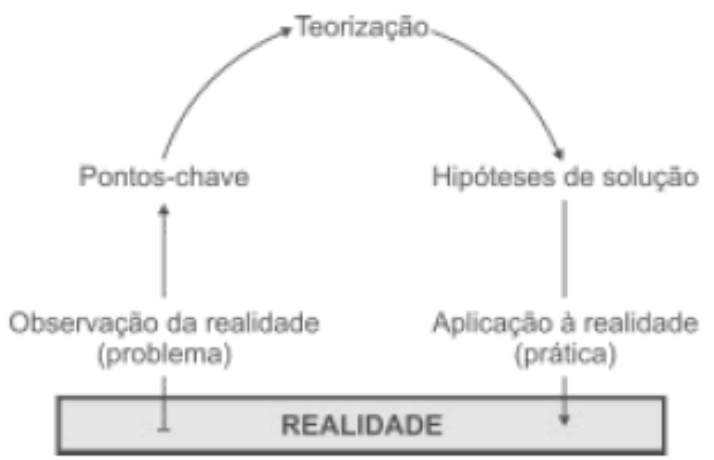

Figura 1 - Metodologia da Probletização

Fonte: Berbel (1998; 1999; 2012) e Colombo e Berbel (2007)

1. Observação da realidade concreta. Observação atenta do aluno e registro sobre o que percebe de uma parcela da realidade, podendo ser dirigidas questões gerais para focalizarem os temas. Devem identificar dificuldades, falhas, contradições, discrepâncias, conflitos etc., que podem configurar-se como problemas. Quando se aproxima dessa realidade a ser observada, os participantes trazem consigo alguns saberes advindos de fontes diversas que, ao serem confrontados com as informações da realidade, permitem problema- 
tizar a realidade, isto é, interagir saberes prévios com aqueles construídos frente à realidade. É momento de problematização: formular o problema (uma questão, afirmação ou negação) a partir de fatos observados, por entendê-los como instigantes. Elege-se um problema com critérios (o que tem mais urgência, necessidade de estudo e qual apresenta maior possibilidade de se atuar sobre ele). Há, então, justificativas para a escolha do problema, entre as quais, as possíveis contribuições para o estudo e para o meio. Esta etapa possibilita ao aluno postura crítica, envolvimento intelectual e político.

2. Determinação de pontos-chave. Momento de definição do que vai ser pesquisado sobre o problema. Os educandos refletirão sobre os possíveis fatores do problema em estudo. Por que será que esse problema acontece? Depois da reflexão inicial dos possíveis fatores associados ao problema são pensados também os seus possíveis determinantes maiores, como reflexão para compreendê-lo melhor através da interrogação sobre os possíveis fatores e determinantes ligados ao problema numa dimensão contextual mais ampla. Com isso, é produzida uma percepção de multideterminação do problema e de sua complexidade, como os elementos políticos, econômicos e éticos, entre outros, envolvidos na questão levantada. Assim, os educandos vão elaborando os pontos essenciais a serem estudados para compreender mais profundamente o problema e encontrar formas de interferir na realidade. São eleitos os pontos considerados prioritários ou mais relevantes, que indicarão caminhos para solucionar o problema. Esse é o momento da análise reflexiva em que o professor estimula os alunos na produção de uma nova síntese e no conjunto dos tópicos a serem investigados.

3. Teorização: etapa do estudo, da investigação. É a etapa investigativa, em que os alunos buscam conhecimentos e informações acerca do problema em variadas fontes, com o uso de diferentes estratégias ou formas de coleta de informações (pesquisa bibliográfica, entrevistas, consultas a especialistas etc.) que são analisadas e avaliadas de modo a servirem de base para a transformação da realidade. É o momento que os educandos adquirem uma consciência maior daquele problema e de sua influência para o meio social.

4. Hipóteses de solução. Etapa que criativo e reflexivo é mobilizado para pensar de modo inovador. Perguntas dessa etapa são: o que é necessário acontecer para que se chegue à solução do problema? O que deve ser providenciado? O que pode ser feito, de fato? Os participantes projetam ideias com base na teorização, que poderão se transformar em ações concretas para solucionar ou desencadear caminhos de solução para o problema. A formulação das hipóteses de solução deve ser norteada pela percepção do problema e pela compreensão teórica adquirida pelos alunos. Todo o estudo deverá fornecer elementos para os alunos elaborarem soluções.

5. Aplicação prática à realidade. Esta é a etapa da efetuação das hipóteses de solução mais viáveis, sendo analisadas e escolhendo-se as que poderão ser realizadas e atingirão o problema em algum grau, contribuindo para a transformação da realidade estudada. Promove transformação, mesmo que pequena. Momento de planejamento e execução, desenvolvimento de um compromisso social, profissional e político. Permite ampliar o conhecimento para o meio estudado, percebendo-se, os participantes, como sujeitos ativos para a cidadania. O caráter prático faz com que os alunos tomem decisões e executem-nas, demarcando um componente social e político em sua formação e ajudando-os a desenvolverem o compromisso com a transformação da realidade observada. É importante e necessário garantir alguma forma de aplicação concreta do estudo, no mínimo a ação de socializar o conhecimento adquirido. 
Há também, dentre opção de inovação pedagógica para responder a esta filosofia de formação, o uso do portfólio reflexivo no processo de ensino-aprendizagem pois permite ao estudante oportunidades para refletir, diagnosticar as suas dificuldades, auto-avaliar o seu desempenho e auto-regular a sua própria aprendizagem. O portfólio tem sido utilizado em várias áreas de formação profissional, cumprindo um papel importante em vários contextos educativos, como estratégia que potencializa a construção do conhecimento de forma reflexiva, com vista a uma progressiva emancipação dos sujeitos em formação (SILVA; SÁ CHAVEZ, 2008).

Tais ferramentas de inovações pedagógicas carregam potencial significativo para a formação de pedagogos. Entretanto, é necessário compreender a complexidade do cenário atual que envolve o ensino superior e suas crises, como: o papel e o trabalho do professor, o protagonismo estudantil, a lógica do conteúdo abordado (disciplinas, currículos e experiências) e a dimensão ética e valores sociais (CUNHA, 2004; CUNHA, 2008).

Assim, pautada em oferecer uma formação de qualidade e que considere a utilização de inovações pedagógicas na formação de pedagogos, uma Instituição de Ensino Superior do interior paulista, busca desenvolver, em uma de suas disciplinas oferecidas ao segundo ano do curso de Pedagogia, práticas de ensino problematizadoras, com inovações pedagógicas, através da Metodologia da Problematização com o Arco de Marguerez e portfólio reflexivo. Tal disciplina, denominada "Pesquisa em Educação", procura trabalhar com intervenções educativas aplicadas pelos graduandos com a realidade, comunidade, favorecendo um diálogo entre Ensino Superior e Comunidade, numa relação teoria e prática contínua.

Desta forma a disciplina e suas inovações pedagógicas com os alunos participantes, são objetos de estudo da pesquisa de Pós Doutorado que pretende contribuir e beneficiar a discussão sobre formação em pedagogia coerente com as demandas sociais atuais e identificar as potencialidades e fragilidades destas inovações pedagógicas para a construção de novos caminhos que orientem o futuro profissional da educação e outras profissões das humanidades e da saúde.

Justifica-se, o interesse em estudar as aplicações da Metodologia da Problematização e o portfólio reflexivo, pois tratam-se de inovações pedagógicas que carregam potenciais para à formação de pedagogos, contribuindo para uma atuação consciente e criativa na realidade, estimulada pelo papel da educação como prática social que entende o homem em sua relação com o mundo e sobre o mundo.

Para a realização da investigação, elaborou-se o seguinte objetivo: relatar as contribuições da Metodologia da Problematização e do portfólio reflexivo na formação do pedagogo, bem como os desafios que os cercam na formação de pedagogos.

\section{Procedimentos Metodológicos}

Trata-se de um estudo exploratório e descritivo, através de relato de experiência, sobre o desempenho dos alunos com a Metodologia da Problematização e com o uso do portfólio.

Este estudo trabalha com a dimensão exploratória no sentido atribuído por Triviños (1987, p. 132), de "esboçar novas linhas de perspectivas de análise e de interpretação no aprofundamento do conhecimento do problema”. Isto porque a investigação desta pesquisa permite maior familiaridade entre o pesquisador e o tema pesquisado, procura ainda abranger amplamente a compreensão do problema do estudo, através da análise das diversas fa- 
ces que compõem a situação chave do estudo. Além disso, trata-se de uma temática que possui lacunas que abrem espaço para sondagens que visem aproximar questões que merecem atenção, apontando tendências para contribuir no estado da arte do conhecimento (TOBAR; YALOUR, 2001). Assim, o estudo buscará através da observação participante e análise de portfólios reflexivos, explorar os significados que estes têm para o processo formativo.

A dimensão descritiva do estudo focaliza-se no sentido de apontar as características de uma situação a ser investigada, experiência e perfil dos participantes, coletando diversas informações, correlacionando-as e descrevendo os achados. A finalidade é mostrar eventos que permitam retratar a realidade de forma completa e profunda, ou seja, proporcionando uma nova visão dos fatos, buscando responder ao problema do estudo (SEVERINO, 2004). Desta forma, serão descritas as experiências dos participantes nas práticas de ensino problematizadoras com intervenções com a realidade e com o portfólio reflexivo.

Para a coleta e validade dos dados foram utilizadas várias fontes e instrumentos para retratar a realidade foco do estudo de maneira abrangente: observação participante e uso do portfólio reflexivo.

Optou-se pela técnica da observação participante, controlada e sistemática por ser mais usada em pesquisas em educação. Para Ludke e Andre (1986) a decisão sobre a extensão do período de observação deve depender do tipo de problema que está sendo estudado e do propósito do estudo, o que justifica o período de coleta de dados. Porém, os autores explicam que a observação torna-se uma técnica científica a partir do momento em que passa por sistematização, planejamento e controle da objetividade, uma vez que, o pesquisador, através de uma visão "treinada", busca acontecimentos específicos (QUEIROZ et al, 2007).

Isto significa que o pesquisador deve ter um planejamento rigoroso das suas ações de "o que" e o "como" observar para atingir os objetivos traçados na pesquisa e sistematizar um olhar apurado sobre a realidade, buscando descobrir o máximo de variáveis explicativas possíveis. A observação aplicada neste estudo então será participante, ou seja, o pesquisador observa a realidade ao mesmo tempo em que interfere e é influenciado por ela (BRANDÃO, 1999).

Tal técnica, necessita de roteiro básico de elaboração observado pelo pesquisador, para oferecer condições a este em descrever sistematicamente as situações e pessoas do seu objetivo de pesquisa abrangendo múltiplos aspectos determinantes da realidade (LUDKE; ANDRE, 1986).

O período de observação foi de 06 meses letivos e teve como foco o desempenho dos alunos em relação às etapas sistematizadas da Metodologia da Problematização, descritas anteriormente.

A cada dia de aula na disciplina que ocorreu semanalmente foi elaborado previamente o roteiro de observação pelo pesquisador os itens a serem observados naquele momento e naquele espaço, tempo da observação, local, objetivo da aula, detalhes do ambiente.

O uso do portfólio reflexivo no presente trabalho, justifica-se pois sua construção pelos graduandos de pedagogia compreende a dupla dimensão (reflexiva e avaliativa) da formação. Para tanto, os estudantes organizam seus portfólios registrando suas produções reflexivas sob a forma de narrativas que cobrem o processo de ensino-aprendizagem na disciplina em questão. Na sua narrativa, o estudante também é estimulado a um processo reflexivo sobre seu próprio processo de construção de conhecimento, mediante o questionamento e os princípios de construção de uma profissionalidade reflexiva, participante e contextualizada (GRILO; MACHADO, 2005).

Para a construção do conhecimento, o portfólio é organizado em narrativas relativas às situações de aprendizagem com inserção de outros elementos para além da mera descrição dos fatos identificando os significa- 
dos dos fenômenos, o papel dos contextos na determinação dos fatos e, ainda, sobre novas possibilidades e funções que poderão vir a ser desempenhadas à luz de novas percepções dos problemas (NUNES; MOREIRA, 2005).

Silva e Sá Chaves (2008) salientam que esta estratégia permite ao profissional em formação, uma ampliação e diversificação do seu olhar, estimulando a tomada de decisões, a necessidade de fazer opções, de julgar, de definir critérios, de se deixar invadir por dúvidas e por conflitos, para deles poder emergir mais consciente, mais informado, mais seguro de si e mais tolerante quanto às hipóteses dos outros.

Assim, o portfólio reflexivo cumpre um papel importante em vários contextos educativos, como estratégia que potencializa a construção do conhecimento de forma reflexiva, com vista a uma progressiva emancipação dos sujeitos em formação.

Apóstolo (2005) também refere, em seu estudo, o impacto que a construção do portfólio reflexivo tem na aprendizagem e no desenvolvimento de graduandos e aponta como vantagens: o desenvolvimento pessoal e grupal; a aprendizagem reflexiva e crítica e não rotineira; o desenvolvimento de competência de planejamento e da capacidade de pesquisa.

Entretanto, o portfólio por ser uma ferramenta pedagógica, necessita contemplar alguns itens em sua elaboração para atingir suas finalidades de ensino e aprendizagem. Sobre os itens a serem incluídos na construção do portfólio pelos alunos e verificados pelo professor e pesquisador, tem-se:

1. Introdução pessoal (um pouco da sua história, gostos pessoais, por que escolheu pedagogia, trajetória profissional, trajetória acadêmica, projetos futuros, expectativas quanto a disciplina);

2. Relato das atividades (descrição das aulas semanais: o que foi trabalhado, atividades em sala com fundamentação teórica dos conceitos, novas aprendizagens, seu envolvimento, desempenho da turma, questões reflexivas);

3. Estudos independentes (leituras e materiais extras a partir do interesse e necessidade de ir-se além dos conteúdos selecionados);

4. Auto-avaliação (reflexão crítica sobre o seu aprendizado, objetivos alcançados, pontos a serem melhorados);

5. Avaliação Construtiva (críticas e comentários sobre o período, indicando pontos positivos e a melhorar, e como melhorar).

Desta forma, o pesquisador trabalhará com a descrição das informações dos portfólios reflexivos, construídos individualmente por cada aluno, ao final da disciplina com base em um roteiro com elementos que facilitem a localização destes itens acima descritos e dados relevantes dos alunos.

A intenção em utilizar o portfólio como ferramenta de coleta de dados é verificar como os alunos sistematizaram seu raciocínio diante da intervenção educativa a ser realizada, como elaboram suas sínteses com conteúdos interdisciplinares, como relatam as aprendizagens, seu envolvimento e desempenho no grupo.

O presente estudo focaliza sua investigação em uma disciplina oferecida aos graduandos do segundo ano de pedagogia, de uma Instituição privada de Ensino Superior, que busca trabalhar com a Metodologia da Problematização com o Arco de Maguerez e o uso do portfólio reflexivo como estratégias de ensino e aprendizado, através de intervenções educativas aplicadas pelos graduandos com a realidade e comunidade, favorecendo um diálogo entre Ensino Superior e Comunidade numa relação teoria e prática contínua.

O estudo realizou-se em 2017 com a participação de 20 alunos, sujeitos da pesquisa. Como critério de inclusão, justifica-se a escolha do estudo com os alunos do segundo ano de Pedagogia devido ao oferecimento da referida disciplina, de acordo com a Grade Curricular da Instituição de Ensino vigente, pelo fato de estarem 
mais bem familiarizados com as demais disciplinas oferecidas pelo curso e pelo fato da pesquisadora ministrar a disciplina o que oferece um contato direto e prolongado com os alunos e seus desenvolvimentos e também com a organização dos conteúdos a serem trabalhados.

Nessa perspectiva, este estudo teve como ponto de partida a seguinte pergunta: Como a Metodologia da Problematização e o uso do portfólio reflexivo podem contribuir na formação de pedagogos, já que tratam-se de inovações pedagógicas?

De modo a responder ao problema de estudo, os dados foram tratados separadamente para estabelecer posteriormente as possíveis relações associando-os ao referencial teórico utilizado: autores da educação que discutem a educação problematizadora, metodologia da problematização e ensino superior.

O presente estudo foi aprovado pelo Comitê de Ética em Pesquisa (CEP) da Faculdade de Medicina de Botucatu - Unesp CAAE: 67125417.6.0000.5411 no mês de maio de 2017.

\section{Resultados e discussão}

Iniciaram-se os trabalhos em agosto de 2017 explicando as etapas da Metodologia do Arco de Marguerez e apresentação sobre portfólio aos alunos de graduação, diante desta inovação de trabalho pedagógico.

A este respeito Severino (2001) destaca ainda que a formação dos professores deve superar a habilitação apenas em técnica, centrada no domínio de informações específicas, mas voltar-se para a mobilização da conscientização do potencial da humanidade, criatividade, reconhecimento das diferenças na sala de aula, comprometimento ético e sócio-político e elaboração de ações que correspondas às necessidades sociais.

Assim, relata-se a aplicação da Metodologia com o Arco de Marguerez e as etapas, que foram feitas em outubro e novembro do mesmo ano:

1. Observação da realidade concreta. Os graduandos, inicialmente, fizeram uma visita técnica a uma escola de ensino fundamental particular utilizando roteiros de observação e de entrevista, elaborados previamente, com a direção responsável pelo local para, posteriormente, desenvolverem uma intervenção baseada em uma demanda escolar. O roteiro de observação recaiu basicamente sobre a estrutura física, aspectos metodológicos, perfil dos professores e alunos e a entrevista centralizou o algumas questões específicas como: concepção de ensino, finalidade da escola, parceria com a família, dificuldades enfrentadas pela equipe escolar e gestora. Foi possível identificar que os graduandos tiveram a possibilidade de verificar o cotidiano da escola por eles visitada, metodologias, perfil dos alunos, organização didática, e as fragilidades da mesma, como a aplicação de ações educativas com o tema "educação emocional infantil" trabalhada de forma tradicional, com pouco diálogo, somente com cartazes e textos, revelando falta de mobilização das crianças e dificuldade da percepção sobre as emoções que apresentam. Foram observadas algumas ações referentes às emoções trabalhadas com os alunos do Ensino Fundamental, porém de uma forma vertical, pouco participativa, como elaboração de cartazes e textos e enfatizados emoções positivas pelas crianças.

2. Determinação de pontos-chave. Após a delimitação da demanda observada e eleita pelos alunos como preocupante (educação emocional infantil), foram elencados alguns tópicos que envolvem e influencia, essa questão, como psicologia infantil; emoções infantis; didática; ensino tradicional x dialógico; família, ensino 
privado x publico, formação de professores, educação emocional, comportamento infantil.

3. Teorização. Os graduandos com o tempo apropriaram-se das teorias que envolvem a psicologia e educação emocional, realizando ponte entre disciplinas do curso e compreendendo a criança como ser integral, sujeito de necessidades físicas, sociais e psicológicas.

Nesse sentido, Cunha (2010) destaca, também, que é chegada a hora de considerar o perfil de um professor que se distancia do quem sabe fazer, sabe ensinar, passando para quem sabe pesquisar, sabe ensinar, ou seja, o conhecimento prático, específico, não garante suportes de ensino ao professor, pois aquele que possui espírito investigador tem mais repertório para efetuar os processos de ensino/aprendizagem.

4. Hipóteses de solução. Nessa etapa os alunos puderam elaborar possíveis respostas para o problema encontrado e construíram coletivamente uma intervenção educativa que contribuísse na escola de forma dialógica com as crianças. Como ferramentas didáticas utilizamos a aula dialogada o que causou um pouco de estranhamento por parte de alguns docentes da IES, pois os alunos participaram ativamente relatando suas opiniões, sobre o tema educação emocional e foi feita ainda uma simulação da atividade a ser aplicada na escola. Foi estipulado que os alunos confeccionariam uma "caixa das emoções", utilizando caixa de papelão e imagens da internet que retratassem as emoções positivas e negativas mais freqüentes na infância para assim problematizar com as crianças e levantar situações referentes ao tema sorteado por elas.

5. Aplicação prática à realidade. Assim, a partir das demandas levantadas em visita técnica anteriormente executada, os graduandos retornaram ao colégio com uma intervenção educativa. A questão da educação emocional foi abordada utilizando uma metodologia dialógica com as crianças por meio de troca de experiências com as emoções mais freqüentes na infância, as positivas e as negativas de forma que as crianças pudessem se expressar, se identificar em mais de uma situação levantada e auxiliar na elaboração de solução de conflitos de classe. Os graduandos foram divididos em grupos de 5 pessoas e direcionadas as salas dos 1 ano ao 5 ano onde através de uma "caixa das emoções" puderam realizar um sorteio com imagens de emoções como: frustração, angustia, medo, amor, solidariedade, ciúmes, tolerância, alegria entre outros.

As crianças da escola então através de sorteio uma a uma retiravam da caixa uma emoção ilustrada com imagens lúdicas e a partir disso eram problematizados: você já sentiu isso, como foi, o que fez, como fazer para melhorar isso. Foram observadas algumas situações como perdas de entes queridos, frustração por algum objetivo não alcançado (skate), ciúmes do irmão mais novo, angustia e preocupação com mães e animais de estimação, solidariedade com uma pessoa carente, tolerância com as diferenças. Notou-se participação dos escolares e curiosidade frente à nova metodologia adotada com o tema.

Em vários momentos foi possível observar os graduandos emocionados e até que se identificavam nas situações. Ressalta-se que a relação teoria e prática permitiu o entendimento dos graduandos sobre a proximidade entre educação e psicologia, favoreceu a capacidade comunicacional, permitiu a interdisciplinaridade, auxiliou no desenvolvimento da criatividade e do trabalho em equipe, ferramentas essenciais ao profissional da educação qualificado. Foram atendidos 60 alunos de 6 a 10 anos no período de 04 horas, das $13 \mathrm{~h}$ as $17 \mathrm{~h}$.

É possível afirmar, desta forma, o cumprimento das etapas da Metodologia da Problematização com o Arco de Marguerez pelos alunos de Pedagogia, que foram orientados nesta sistematização, e as consideráveis contribuições às suas formações enquanto educadores. 
A problematização tem sido muito utilizada como estratégia de ensino e aprendizagem, por apresentar uma abordagem pedagógica que estimula a participação do educando, desenvolvendo a autonomia e a compreensão da responsabilidade individual e coletiva no processo de aprendizagem (COTTA et al., 2012).

Entretanto, Berbel (1998) sinaliza ser adequado utilizar a metodologia da problematização em situações em que sobressaiam o caráter político, econômico e social, já que carrega o potencial de trabalhar com temas relacionados com a vida em sociedade.

Foi solicitado ainda aos graduandos que fizessem um portfólio sobre as experiências durante os seis meses de trabalho e estudos.

Grilo e Machado (2005) referem como benefícios do uso do portfólio: a oportunidade para um processo reflexivo mais sistematizado e continuado; um espaço de questionamento sistemático sobre a prática em situações de trabalho; a promoção do desenvolvimento do formando a partir das suas próprias experiências; a oportunidade para desenvolver processos de auto-avaliação e de autoconhecimento do formando e a oportunidade de uma avaliação mais autêntica, mais dinâmica, mais fundamentada e mais participada.

Analisando os portfólios, no entanto, verificou-se que foram fracos e o que revela que o uso desse tipo de inovação pedagógica com o uso do portfólio é uma prática importante já que desenvolve a sistematização do raciocínio e criatividade, porém não utilizada com freqüência no curso de pedagogia da referida Instituição Colaboradora revelando ainda dificuldade dos graduandos na organização do registro das informações e falta de conhecimento desta prática inovadora em educação. Foi a primeira experiência da turma investigada com o uso do portfólio, o que demonstra a importância dessa prática ser mais recorrente. Alguns alunos tinham experiência com o portfólio em função do Programa Escola da Familia em que participam como voluntários, isso ajudou na organização das informações e elaboração do portfólio.

Destaca-se ainda que os alunos do presente estudo apenas copiaram o que estava no caderno em relação ao dia da aula. Foram limitados, escrevendo em tópicos o que foi observado. Poucos colocaram conclusões sobre a aula, aprendizagens. Alguns trabalharam com desenho feito a mão porém muitos não saíram do convencional, a maioria ficou presa no dia, a interdisciplinaridade foi observada em poucos, com a psicologia, didática e sociologia.

Resultados bastante semelhantes foram encontrados em Costa e Cotta (2014), onde pesquisaram a prática de portfólio na graduação em que os estudantes relataram a falta de conhecimento do que vem realmente a ser o portfólio e qual a sua real importância.

Outro estudo de Cesário et al (2016) evidenciou que os estudantes assumem a falta do hábito de escrever sobre si mesmo, registrar subjetividades, reflexões, dúvidas, sentimentos e análises sobre o vivido na academia; e a preocupação acerca da interpretação de tais registros que seria feita pelos professores. Tais elementos pesam na elaboração do portfólio.

Os alunos não se dedicaram quanto o esperado, a maioria achou que seria suficiente colocar em tópicos e pasta plástica , mas revela: insegurança quanto ao uso do portifólio, fraqueza do curso em não proporcionar mais momentos assim e limitação do aluno em sistematizar e uma fragilidade do professor-pesquisador da disciplina em explorar mais e fazer mais links e significação com o uso desta ferramenta.Os relatórios não fizeram articulação com a teoria, não buscaram nada além do dado em aula, se centralizaram em tópicos, copias do caderno e slides, as reflexões foram limitadas "gostei da aula", "não gostei da aula".Alguns se destacaram por terem feito conclusões , revelando a práxis do professor e também uma auto-avaliação de emprenho do próprio aluno , mas 
não houve busca de teoria. Os relatos das atividades práticas se limitaram a fotos com poucas descrições com salvas exceções que trouxeram conexões com outras disciplinas.

Tais ferramentas de inovações pedagógicas carregam potencial significativo para a formação de pedagogos (Metodologia da Problematização e portfólio). Entretanto, é necessário compreender a complexidade do cenário atual que envolve o ensino superior e suas crises, como: o papel e o trabalho do professor, o protagonismo estudantil, a lógica do conteúdo abordado (disciplinas, currículos e experiências) e a dimensão ética e valores sociais (SILVA; SÁ CHAVEZ, 2008).

Conforme os autores, Cotta et al (2012) explicam, torna-se importante orientar os alunos à sistematização da compreensão sobre portfólio e seu significado na aprendizagem, por meio do estudo na literatura específica a fim de alcançar a elaboração de sentidos para uso satisfatório desta ferramenta.

Isto desafia os docentes a modificar suas práticas de ensino na perspectiva de proporcionar uma melhor aprendizagem para os discentes, ampliando sua prática para além da dimensão técnica/científica de sua formação, requerendo saberes de diferentes natureza e práticas inovadoras através de rupturas com a prática de ensino tradicional (CUNHA, 2004; CUNHA, 2008).

\section{Conclusão}

Foi possível identificar que os graduandos, através da Metodologia da Problematização com o Arco de Marguerez, tiveram a possibilidade de verificar o cotidiano da escola por eles visitada, metodologias, perfil dos alunos, organização didática, e as fragilidades da mesma, e a oportunidade de aplicação de ações educativas com o tema emoções e sentimentos infantis, demandas observadas em um primeiro momento, trabalhadas de forma tradicional, com pouco diálogo, somente com cartazes e textos, revelando falta de mobilização das crianças e dificuldade da percepção sobre as emoções que apresentam. Assim, com o tempo, os graduandos apropriaram-se das teorias que envolvem a psicologia e educação emocional, por meio da teorização, e elaboraram uma intervenção educativa que contribuísse na escola de forma dialógica com as crianças.

Ressalta-se que a relação teoria e prática permitiu o entendimento dos graduandos sobre a proximidade entre educação e psicologia, favoreceu a capacidade comunicacional, permitiu a interdisciplinaridade, auxiliou no desenvolvimento da criatividade e do trabalho em equipe, ferramentas essenciais ao profissional da educação qualificado. Percebeu-se o cumprimento das etapas da Metodologia da Problematização com o Arco de Margurez pelos alunos que foram orientados nesta sistematização e as consideráveis contribuições às suas formações enquanto educadores. Entretanto as práticas do uso do portfólio deixaram a desejar, revelando dificuldades dos alunos tanto no registro das informações, quanto na síntese do conhecimento e a baixa freqüência desta inovação pedagógica na graduação em Pedagogia desta Instituição investigada.

Desta forma a presente investigação contribui na medida que beneficia a discussão sobre formação em pedagogia coerente com as demandas sociais atuais e identificar as potencialidades e fragilidades destas inovações pedagógicas para a construção de novos caminhos que orientem o futuro profissional da educação e outras profissões das humanidades e da saúde.

Investigar os desempenhos dos alunos do ensino superior do curso de Pedagogia através de inovações pedagógicas é traçar novos rumos que promovam uma geração mais consciente de seu tempo e espaço e assim, contribuir numa transformação social e política. 


\section{Referências}

APÓSTOLO, J. A metodologia de "portfolio" no ensino de enfermagem. In: SÁ-CHAVES, I. (Org.) Os "portfolios" reflexivos (também) trazem gente dentro: reflexões em torno do seu uso na humanização dos processos formativos. Porto:Porto Editora, 2005, p.49-159.

BACKES, V. M. S. et al. Competência dos enfermeiros em problematizar a realidade do serviço de saúde no contexto do Sistema Único de Saúde. Texto Contexto - Enferm. V.16, n.4, p.727-736, 2007.

BERBEL, N.A.N. A problematização e a aprendizagem baseada em problemas: diferentes termos ou diferentes caminhos? Comunic. Saúde, Educ., v.2, n.2, p.139-154, 1998.

BERBEL, N.A.N. Aspectos pedagógicos e filosóficos da Metodologia da Problematização. In: Metodologia da problematização: fundamentos e aplicações. Londrina: Ed UEL, 1999.

BERBEL, N. A. N. A Metodologia da Problematização em três versões no contexto da didática e da formação de professores. Rev. Diálogo Educ., v. 12, n. 35, p. 101-118, 2012.

BORILLE, D.C .et al. A aplicação do método do arco da problematização na coleta de dados em pesquisa de enfermagem: relato de experiência. Texto Contexto Enferm., v.21, n.1, p. 209-216, 2012.

BRANDÃO, C.R. Repensando a pesquisa participante. São Paulo: Brasiliense, 1999.

COLOMBO, A. A.; BERBEL, N. A. N. A metodologia da problematização com o Arco de Maguerez e sua relação com os saberes de professores. Semina: Ciên. Soc. Hum., v. 28, n. 2, p. 121-146, 2007.

CESÁRIO, J.B. Et al Portfólio reflexivo como estratégia de avaliação formativa. Revista Baiana de Enfermagem, Salvador, v. 30, n. 1, p. 356-364, 2016.

CUNHA, M. I. O bom professor e sua prática. Campinas: Papirus, 1989.

CUNHA, M. I. Inovações Pedagógicas e a reconfiguração de saberes no ensinar e no aprender na Universidade. In: CONGRESSO LUSO-AFRO-BRASILEIRO DE CIÊNCIAS SOCIAIS. 8., 2004, Coimbra. Anais... Coimbra, setembro de 2004.

CUNHA, M. I. Inovações pedagógicas: o desafio da reconfiguração de saberes na docência universitária. Cadernos Pedagogia Universitária, USP, 2008.

CUNHA, M. I. Qualidade do ensino de graduação: relação entre pesquisa, ensino e desenvolvimento profissional docente. Projeto de pesquisa. Porto Alegre-RS: UNISINOS, 2010.

COSTA, G.D, COTTA, R.M.M. "Learning-by-doing”: social representations of healthcare students regarding reflective portfolio as a teaching, learning and assessment method. Interface (Botucatu), v.18, n.51, p. 771-83, 2014.

COTTA, R.M.M. et al. Construção de portfólios coletivos em currículos tradicionais: uma proposta inovadora de ensino-aprendizagem. Ciênc. Saúde Coletiva, v. 17, n. 3, p.787-796, 2012.

CYRINO, E.G.; PEREIRA, T.M.L. Trabalhando com estratégias de ensino-aprendizado por descoberta na área da saúde: a problematização e a aprendizagem baseada em problemas. Cad. Saúde Pública, v.20, n.3, p.780-788, 2004.

CYRINO, E.G.; RIZZATO, A.B.P. Contribuição à mudança curricular na graduação da Faculdade de Medicina de Botucatu. Rev. Bras. Saúde Mater. Infant. v.4, n.1, p.59-69, 2004.

FREIRE, P. Pedagogia da autonomia: saberes necessários à prática educativa. 25. ed. São Paulo: Paz e Terra, 2002. 
FREITAS, R.A.M.M. Ensino por problemas: uma abordagem para o desenvolvimento do aluno. Educ. Pesqui., In press, 2011.

GRILO, J.M; MACHADO, C.G. "Portfólios" reflexivos na formação inicial de professores de biologia e geologia: viagens na terra do eu. In: SÁ-CHAVES, I. (Org.) Os "portfólios" reflexivos (também) trazem gente dentro: reflexões em torno do seu uso na humanização dos processos formativos. Porto: Porto Editora; 2005. p.21-49.

QUEIROZ, et al. Observação participante na pesquisa qualitativa: conceitos e aplicações na área da saúde. R Enferm UERJ, Rio de Janeiro, v. 15, n. 2, p. 276-83, 2007.

LUDKE, M.; ANDRÉ, M. E. D. A. Pesquisa em educação: abordagens qualitativas. São Paulo: EPU, 1986.

MARIN, M.J.S. et al. Aspectos das fortalezas e fragilidades no uso das metodologias ativas de aprendizagem. Rev. Bras. Educ. Med., v.34, n.1, p.13-20, 2010.

MIRANDA, K.C.L.; BARROSO, M. G. T. A contribuição de Paulo Freire à prática e educação crítica em enfermagem. Rev. Latino-Am. Enf., v.12, n.4, p. 631-635, 2004.

MITRE, S.M.et al. Metodologias ativas de ensino-aprendizagem na formação profissional em saúde: debates atuais. Ciênc. Saúde Coletiva, v.13, Supl.2, p.2133-2144, 2008.

NUNES, A.; MOREIRA, A. O "portfólio" na aula de língua estrangeira: uma forma de aprender e a ser (para alunos e professores). In: SÁ-CHAVES, I. (Org.). Os “portfólios” reflexivos (também) trazem gente dentro: reflexões em torno do seu uso na humanização dos processos formativos. Porto: Porto Editora, 2005. p.51-66.

PIMENTA, S. G.; ANASTASIOU, L. G. Docência no ensino superior. 4. ed. São Paulo: Cortes, 2010.

RODRIGUES, R.M.; CALDEIRA, S. Movimentos na educação superior, no ensino em saúde e na enfermagem.

Rev. Bras. Enf., v.61, n.5, p.629-636, 2008.

ROMANOWSKI, J.P. Formação e Profissionalização docente. Curitiba: Intersaberes, 2012.

SEVERINO, A. J. Educação, sujeito e história. São Paulo: Olho d'água, 2001.

SILVA, R.F.; SÁ-CHAVES, I. Reflexive formation: teachers' representations about the use of reflexive portfolio in the forming of medical doctors and nurses. Interface - Comunic., Saúde, Educ., v.12, n.27, p.721-34, out./dez. 2008.

TOBAR, F; YALOUR, M. R. Como fazer teses em Saúde Pública. Rio de Janeiro: Editora Fiocruz, 2001.

TRIVIÑOS, A. N. S. Introdução à pesquisa em ciências sociais: a pesquisa qualitativa em educação. São Paulo, Atlas, 1987. 175p.

VILLARDI, M.L; CYRINO, E.G; BERBEL, N.A.N. A metodologia da problematização no contexto da formação em saúde. In: CYRINO, A.P, CYRINO, E.G GODOY, D. Saúde, Ensino e Comunidade: reflexões sobre práticas de ensino na atenção primária à saúde. São Paulo: Cultura Acadêmica, 2014, 252 p.

VILLARDI, M.L; CYRINO, E.G; BERBEL, N.A.N. A problematização em educação em saúde. São Paulo: Cultura Acadêmica, 2015.

ZABALZA, M. A. Uma nova didática para o ensino universitário: respondendo ao desafio do espaço europeu de ensino superior. In: SESSÃO SOLENE COMEMORATIVA DO DIA DA UNIVERSIDADE. 95. aniversário da Universidade do Porto. Porto: Faculdade de Psicologia e Ciências da Educação, mar/2006. 